\title{
AUGMENTED REALITY IN ENGINEERING EDUCATION: OPPORTUNITIES AND ADVANTAGES
}

\begin{abstract}
The article is dedicated to the study of the possibility of applying augmented reality technologies in the field of engineering education. The prerequisites for creation and development of Industry 4.0 are considered. The study considers the concept and the technology of augmented reality. The ground of relevance and timeliness of its application in the professional training education process of engineers from different industrial departments is given. The problems of engineering education are reflected. The modern tendencies of engineering education development are considered. The methods of augmented reality technology application in support for the education process are reflected upon. The advantages and disadvantages of augmented reality technologies' usage in the engineering education are considered.
\end{abstract}

Keywords: Industry 4.0, education process, augmented reality

\section{Introduction}

In the near future, the industry will make a transition to the new technological structure called "Industry 4.0" [1]. The introduction of the "Industry 4.0 " principles will increase production quality, provide the opportunity of fast line reestablishment, which will increase its competitiveness. Besides, the development of these new technologies stimulates innovation and employment.

"Industry 4.0" and its ideas resonate today on different continents and levels. For example, China has a comparable concept called Acceleration as a part of the "China 2025" strategy.

The prerequisites for creation and development of "Industry 4.0" are quite simple and apparent. First of all, if one takes a look at the young generation and people around in general, one will find that the majority uses smartphones, tablets and other gadgets. Secondly, social networks have spread widely: people use them to communicate, share media, work. Lastly, augmented reality technologies have been developed fast. Will such a way of communication gradually move to the industry? From our point of view, it is only a matter of time. In the future, besides the level of human - to - human communication, the machine interaction with other machines will change as well. The term "human machine interface" has quite a different meaning today. Many machines have the ability to inform about their state and offer an appropriate course of action. In the future, they will interact with other machines, barely communicating with humans, which may mean that it is better to use the term "Machine - human interface" $[2,3]$.

Technologies of hybrid (or mixed) reality belong among the components of "Industry 4.0". The general model of hybrid reality (Figure 1) represents the path between Real Environment and Virtual Environment. The transitional links of this model are Augmented Reality - AR and Augmented Virtuality - AV. The $\mathrm{AR}$ is closer to the real environment and the $\mathrm{AV}$ is closer to the virtual environment.

Virtual Reality (VR) and Augmented Reality (AR) have recently been gaining popularity. These technologies provide us with a wide range of opportunities. AR and VR technologies can be applicable almost everywhere from the gaming industry, advertising and presentations (WOW - effect) to industrial and expert systems. AR is capable of turning our world upside down, making it more comfortable, more interactive and safer.

Augmented reality is the new interactive technology, which allows using computer graphics or text on the real - time objects. In comparison to virtual reality, AR - interfaces allow the users to see the virtual objects in reality and to manipulate them in real time [4].

Basically stated, Augmented Reality is the link between ordinary reality and fully virtual reality. Figure 2 shows the process of the Augmented reality appearance. Augmented reality is a real world, which is "completed" by the virtual elements.

The work begins with the camera initialization, the video stream request and the allocation of frame out of the stream.

\footnotetext{
* Aleksandr Nesterov, Ivan Kholodilin, Aleksandr Shishkov, Pavel Vanin

Department of Automated Electric Drives, South - Ural State University, Chelyabinsk, Russia

E-mail: nesterovas@susu.ru
} 

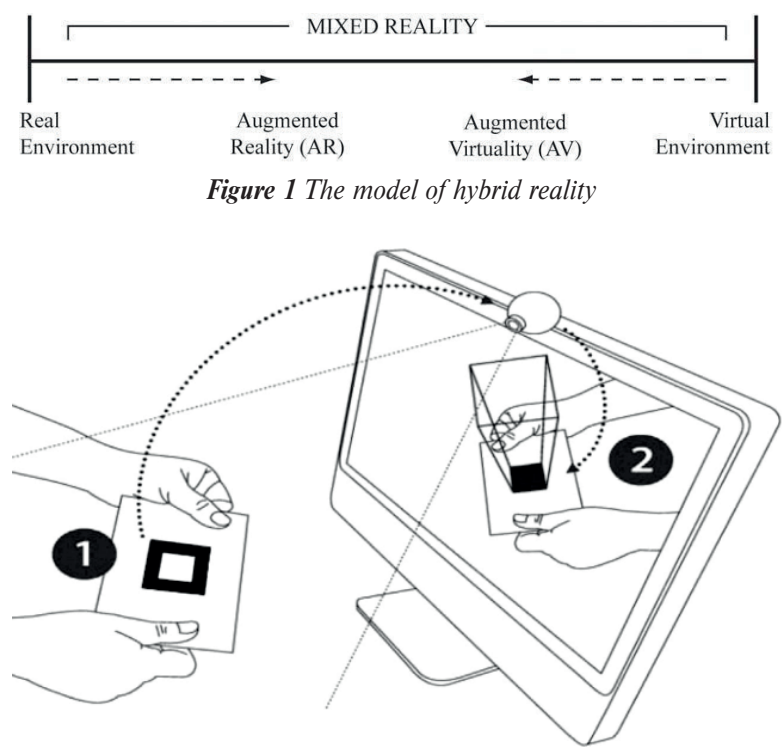

Figure 2 The process of the Augmented Reality appearance

Then, the necessary image, particularly the QR - code, needs to be found. When the code is found, the information is being exported. After this, the application sends a request to the data base in order to find the right object. Next, the information on the screen is supplemented by the visual objects from the data base.

Analysing all of the above, the logical solution is the creation of the mixed environment that includes the perceived environment and the virtual objects added in it. This approach would allow expanding the stream of the information received in time unit and, as a result, to increase the efficiency of work [5].

In other words, Augmented Reality is a combination of two initially independent fields: the world of real objects around the human and the virtual world, created by computer, on the screen. This interactive technology provides the user with an opportunity to use special $2 \mathrm{D}$ and $3 \mathrm{~d}$ objects over the camera image, and by this "completing" the reality [6].

\section{The significance of AR technology application in engineering education}

The question of professional training of engineering from different industrial departments is a timely issue.

The following disadvantages can be highlighted, considering the main problems of engineering education:

- Remoteness of engineer training facilities from real functioning companies;

- Incongruity of the specialists' training cycles and the changes in technology sphere;

- Insufficient number of highly trained teaching staff;

- Absence of systematic discovery of talented people in engineering area;

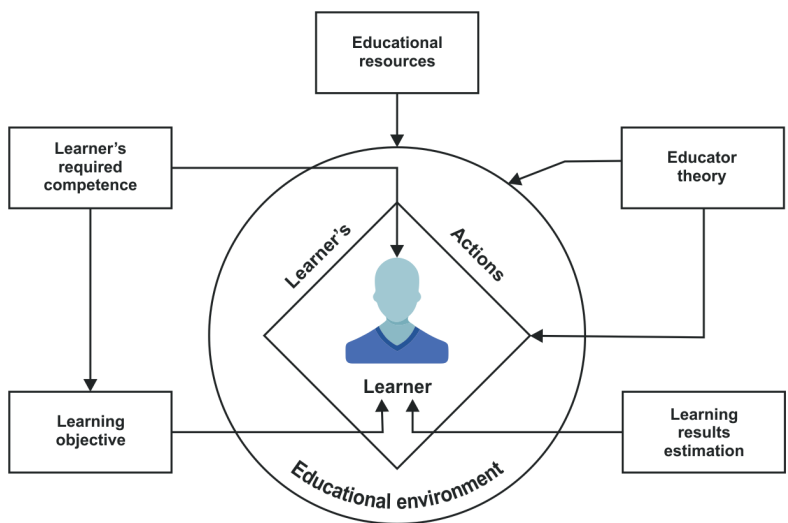

Figure 3 The schematic representation of the MARE methodology

In addition, the following key tendencies of technical specialists training can be noted:

- Creating an education process that is oriented towards integration with industry at the university;

- Using the CDIO (Conceive, Design, Implement, Operate) standard;

- Modelling the objective and social content of the professional work, transforming the educational work of a student into the professional work of a specialist;

- Development and application of the new principles of engineering education integration system with an "immersion" of the student into the professional environment.

The ways of the AR application in education were established quite a long time ago. They are reflected in the MARE (Mobile Augmented Reality Education) methodology (Figure 3).

As it can be seen in the representation above, the AR sphere includes educational resources, the composition of which creates the educational environment.

\section{The advantages of AR technology application in education}

What practical realization are the education resources with the AR supposed to have? Analysing the current educational situation, one can make the conclusion that the best option is the training equipment with augmented reality.

The introduction of AR technologies in the educational process will increase the efficiency of education in technical specialists' training by realizing the following objectives:

1) Realization of the "immersion effect" systems, in which the image is created most realistically. It is known that a human perceives about $80 \%$ of information visually.

2) Creating laboratory complexes which include the $A R$ technologies. There is no need of a rational change of teaching methods. AR will allow expanding the possibilities of a regular training equipment, changing it into an interactive educational complex. It is an evolutionary, not revolutionary way. 
3) Elimination of the digital gap. It is no secret that many educators (considering an average age of university professors which is 50 years in Russia) have difficulty adopting new IT - technologies, which younger people are easily accustomed to. Training equipment with augmented reality will focus on elimination of this gap. The laboratory complex keeps its regular look, but its elements and contents would serve as markers, recognized by the AR application.

4) Transmission of information to a learner by a much wider channel "animation + sound" in addition to the regular channel "laboratory work". The functions of a regular training equipment are rapidly expanding.

5) Increasing the attractiveness of the educational process to a generation that grew up using gadgets.

6) Development of new technologies, which stimulate innovation and employment.

\section{AR methods in education}

The educational process consists of a number of sub processes which need to be actively sustained. One of the ways of the educational process' sustainability is its informational support. It is executed by the implementation of the new communication technologies in educational activity; using these innovative technologies allows completing the traditional methods of education, which help improving the process and accelerating access to the information sources. The informational support consists in increasing the quality of students' and educators' activity, aimed at the formation of a personal information culture, which is oriented to gaining information knowledge and obtaining information skills [7 - 9].

The question of the educational process' support using innovative technologies, particularly the AR technologies, is quite timely due to the increased quality and efficiency being the main objectives.

There are several methods of using the AR technologies in support of the educational process $[10,11]$ :

- Method of using the QR - codes in educational institutions' practice

- Using the QR - codes with a link, leading to the multimedia resources, which help solving a certain problem. Printing the codes, one can put them in the text books or students' handbooks.

- While organizing the project activity, one can use the collection of links, information blocks, comments and other QR - codes. They can be published on websites, posters etc., supporting the project.

- The QR - codes can be put on the information panels as a video or multimedia comment (as a link), in addition to an announcement or other type of material.

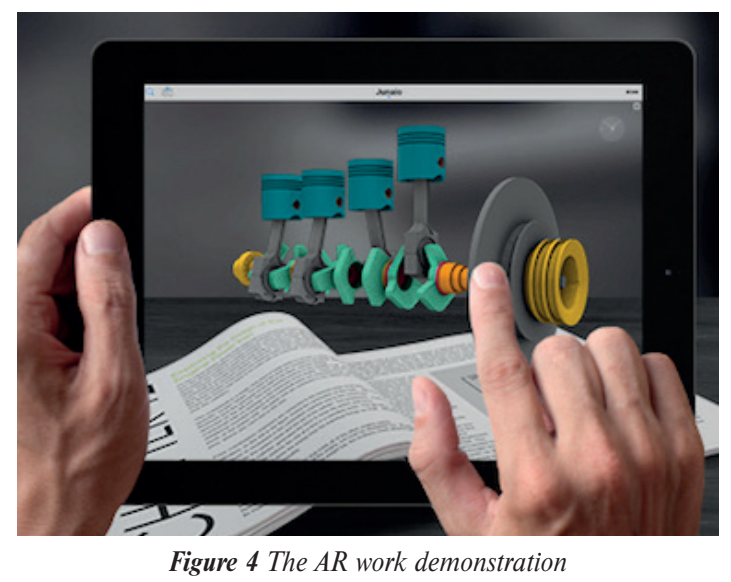

- Putting the code in a university library prospectus: code automatically shows to conclude the general information, table of contents, author and location on the shelf.

- The codes are automatically added in the educational information environment. These codes content directions to the URL - page of a certain educational course, a link to the schedule, availability of vacant lecture halls.

A. The method of using the AR and virtual media objects

- A vivid demonstration of the complex processes. AR allows not only seeing the object, but also understanding what it is made of, how it functions, what has been happening to it in time, how it interacts with other objects. The learners will be able to control not only the material objects themselves, but also the process, for example, the magnetic field effect or the water cycle [8]. Figure 4 demonstrates how AR works.

- Video - streaming. The screen shows certain videos, which explain the topic that is being learned.

- Educational literature with AR [9].

\section{Engineering education technology improvement}

The tendency of recent decades is a constant increasing complexity of different systems, above all those technological in nature. This leads to prolongation of the specialists training, and its quality decrease. Using the active industrial systems is obstructed by a number of reasons: expensive system work time, high degree of risk to one's health/life, and a high price.

One of the ways to perfect the engineering education technologies is using the $\mathrm{AU}$ systems and $3 \mathrm{D}$ educational systems. This will allow a decrease in training time, while increasing the education quality and strengthening the practical part of the educational process:

- Organization of training the learners to model, construct and use AR.

- Making the textbook vivid, by literally controlling the 3D computer models. 
- Adding some change to the educational process, making it more visual and interactive.

- Increasing the level of perception due to students' involvement in the educational process, etc.

As these educational systems are rather complex, the developers must have a special training. In addition, specialists in this field are supposed to be knowledgeable in other areas, such as technical and humanities:

- Readiness to explore the objects, which are represented by complex systems, and to describe them by using adequate models [12];

- Ability to use innovative technologies of the learning systems creation, based on the ideas of the professional performance visualization made by $\mathrm{AR}$ and VR;

- Ability to develop and to implement the educational systems based on 3D - models, as well as on methods and technologies of their application;

- Readiness to update and/or to create new forms and methods, taking into account the conceptual features of 3D E - learning. Today, the main problem of the engineering education is a minimum interaction of those who develop the technologies with those who implement it into the educational system. Among the reasons for this is a lack of financial support give to educational institutions and a low level of awareness about this sort of technologies. The AR technologies are mainly used in medical training. There are many programs, which model the inner structure of an organism, nerve and blood systems etc., with the help of which one can understand it easier and remember the images visually.

\section{Conclusion}

The analysis of AR made in this article shows new horizons in the educational area. Firstly, the implementation of AR technologies stimulates the students to study themselves, catching the audience's interest, developing an aspiration to discover new possibilities, replacing expensive laboratory equipment by multimedia models. Secondly, the real objects can be supplemented by adding context information and the visualization of the learning material, which would increase the level of material perception and interest. And finally, the professional training quality is increased by using the training equipment with AR. The process becomes more interactive and more productive.

In conclusion, it needs to be noted that the AR technologies open new horizons in the training of technical institution graduates, using the right methods and educational systems.

\section{Acknowledgement}

The work was supported by Act 211 Government of the Russian Federation, contract No. 02.A03.21.0011.

\section{References}

[1] GILCHRIST, A.: Industry 4.0: The Industrial Internet of Things. p. 250, 2016.

[2] KRAJCOVIC, M., BULEJ, V., SAPIETOVA, A., KURIC, I.: Intelligent Manufacturing Systems in Concept of Digital Factory. Communications - Scientific Letters of the University of Zilina, 15(2), 77-87, 2013.

[3] KRAJCOVIC, M., GABAJOVA, G., MICIETA, B.: Order Picking Using Augmented Reality. Communications - Scientific Letters of the University of Zilina, 16(3), 106-111, 2014.

[4] MAMONTOV, D. K.: Enriching the Reality: Popular Mechanics (in Russian). 46-48, 2009.

[5] OSKOLKOV, I. A.: Augmented Reality: Such an Augmented Reality (in Russian) [online]. Available: http://www.computerra.ru/ terralab/softerra/448481 (accessed 25.12.2016).

[6] BALOG, A., PRIBEANU, C., IORDACHE, D.: Augmented Reality in Schools: Preliminary Evaluation Results from a Summer School. Proc. of the World Academy of Science, Engineering and Technology, France, 114-117, 2007.

[7] ZAKHAROVA, I. G.: Information Technologies in Education (in Russian). Akademia, 56-59, 2003.

[8] BASHMAKOV, A. I., STARYKH, V. A.: The Principles of Building a Basis for Information Education Open Environments. BINOM, Moscow, 2010.

[9] PEMBERTON, L., WINTER, M.: Collaborative Augmented Reality in Schools [online]. Available: http://tee.org/uploads/ cscl2009/ paper236.pdf.

[10] LeZHeboKOV, A. A., PASCHENKO, S. V.: Possibilities of the Augmented Reality Technologies. Trudy kongressa po intellektualnym sistemam i informacyonnym tehnologiyam (IS - IT'12), Russia, 196-203, 2012.

[11] KHOLODILIN, I. YU., NESTEROV, A. S., SHISHKOV, A. N., SOKHINA A. V.: Industry 4.0: Present and Future. Sovremennye nauchno - prakticheskie reshenija XXI veka: materialy mezhdunarodnoj nauchno - prakticheskoj konferencii, Russia, 270-274, 2016.

[12] KOLAROVSZKI, P., TENGLER, J., PERAKOVIC, D., PERISA, M.: Impact of Sorting Machine on Life Cycle of Passive uhf RFID Tags Placed on Letter Mail. Communications - Scientific Letters of the University of Zilina, 18(2), 143-147, 2016. 